estudos RBEP

\title{
Representações sociais de estudantes do ensino médio sobre problemas ambientais
}

I Universidade Estadual de Maringá (UEM). Maringá, Paraná, Brasil. E-mail: <tania docarmo@hotmail.com>; <https://orcid.org/00000002-6456-9859>.

II Doutoranda em Educação para Ciência e Matemática na Universidade Estadual de Maringá (UEM), Maringá, Paraná, Brasil.

III Universidade Estadual de Maringá (UEM). Maringá, Paraná, Brasil. E-mail: <juniormagalhaes@hotmail. com>; <https://orcid.org/000 0-0002-1116-0777>.

IV Doutor em Ciências pela Universidade Estadual de Maringá (UEM). Maringá, Paraná, Brasil.

v Universidade Estadual de Maringá (UEM). Maringá, Paraná, Brasil. E-mail: $<$ nmmkiouranis@gmail. com>; <https://orcid.org/00 00-0002-1279-9994>.

vI Doutora em Educação para a Ciência pela Universidade Estadual Paulista (Unesp) Bauru, São Paulo, Brasil.

VII Faculdade Gama e Souza. Rio de Janeiro, Rio de Janeiro, Brasil. E-mail: $<$ felipetriani@gmail.com>; $<$ https://orcid.org/00000001-6470-8823>.

${ }^{\text {VIII }}$ Mestre em Humanidades, Culturas e Artes pela Universidade do Grande Rio (Unigranrio). Duque de Caxias, Rio de Janeiro, Brasil.

\section{Tânia do Carmo I, II}

Carlos Alberto de Oliveira Magalhães Júnior ${ }^{\mathrm{III}, \text { IV }}$

Neide Maria Michellan Kiouranis ${ }^{\mathrm{v}, \mathrm{vI}}$

Felipe da Silva Triani ${ }^{\mathrm{VII}, \text { vIII }}$

http://dx.doi.org/10.24109/2176-6681.rbep.99i252.3411

\section{Resumo}

A investigação refere-se às representações sociais de alunos do ensino médio sobre problemas ambientais de uma cidade do noroeste do Paraná e foi motivada pela importância da inserção, no ensino de ciências, das questões ambientais, bem como do seu reconhecimento para a tomada de atitudes. Os dados foram recolhidos por meio da técnica de evocação livre de palavras e analisados segundo a abordagem estruturalista da Teoria das Representações Sociais, em uma turma de primeiro e outra de terceiro ano do ensino médio. Conclui que, nas duas turmas investigadas, há indícios de representações sociais naturalistas dos problemas ambientais.

Palavras-chave: ensino de ciências; meio ambiente; teoria das representações sociais. 


\section{Abstract \\ Social representations developed by high-school students about environmental issues}

This article presents research findings on possible social representations developed by high-school students about the environmental problems of a city in the northwestern Paraná. Reflections on the importance of incorporating environment-related topics in science teaching has motived this work's investigative efforts, as well as the importance of a social recognition of those topics in the action-taking processes. Data collection was undertaken through the word free evocation technique and analyzed in accordance to the structuralist approach of the Theory of Social Representations, in first and second year high-school classes. Results reveal an ongoing necessity of striving for a teaching style that stirs new environment notions, in which social factors are acknowledged as existent; since, through the considerations in the study, it was indicated that two of the classes investigated harbor naturalistic social representations of environmental issues. Thus, this study aims to contribute to the search for reflections and actions that permeate socioenvironmental issues.

Keywords: science teaching; environment; theory of social representations.

\section{Introdução}

Os problemas ambientais têm se destacado nas últimas décadas e se justificam por meio das intensas disparidades nas relações do homem com o meio ambiente, as quais proporcionam crescentes preocupações que envolvem tanto as instâncias governamentais quanto a sociedade em geral. Como exemplo, as questões relacionadas à escassez dos recursos naturais, as várias causas de contaminação, as lutas de comunidades em torno de saneamento básico, os depósitos de lixo em áreas urbanas com grande aglomeração de pessoas e a degradação da qualidade de vida (Dias, 2004; Carvalho, 1998). Nesse sentido, há uma crise ambiental e civilizatória instaurada, decorrente dos complexos processos sociais, econômicos, culturais, éticos, científicos, tecnológicos e geográficos, que são interligados e que podem se manifestar pelo fracionamento do conhecimento e pela deterioração do ambiente, proporcionados pelo logocentrismo da ciência moderna e pela procura desenfreada do desenvolvimento científico e tecnológico (Bazzo, 2010; Leff, 2000; Carvalho, 1998).

Segundo Carvalho (1998), os problemas ambientais são os porta-vozes que deflagram as discussões a respeito das situações de desigualdades entre as classes sociais no acesso aos recursos naturais e às condições ambientais que são essenciais para o bem-estar humano. Dessa forma, os problemas que hoje são encontrados na natureza foram causados pela relação de 
homens e mulheres com o ambiente. Logo, as soluções necessárias para os problemas ambientais terão de partir de todos/as cidadãos/dãs, e não apenas de alguns grupos eleitos para essa função (Reigota, 2012). Nessa perspectiva de busca por soluções para os problemas ambientais, é importante ressaltar o conceito de um meio ambiente que esteja relacionado não apenas aos aspectos naturais, mas também aos valores que estão integrados na vivência social, como política, economia, cultura, moral e ética.

Autores como Oliveira (2000), Jacobi (2000), Leff (2001) e Brugger (1994) discutem os aspectos sociais como integrantes do meio ambiente, ou seja, a natureza não deve ser considerada como pura e intocável, mas sim como o meio onde a ação humana não poderá ser desconsiderada nos processos de transformação que ocorrem devido às interações resultantes das atividades sociais. Nesse cenário de busca pelo equilíbrio das interações sociais com a natureza, tem-se o ensino de ciências como um processo que pode proporcionar momentos de desenvolvimento de novas ideias, reflexões e atitudes (Vasconcelos; Freitas, 2012). Assim, vários assuntos devem ser discutidos, tanto no âmbito social quanto no ambiental, considerando que nem o homem, tampouco a natureza podem ser separados em espaços diferentes de vivência.

No que diz respeito aos aspectos legais, a Lei $\mathrm{n}^{\circ}$ 6.938, de agosto de 1981 - Política Nacional do Meio Ambiente (PNMA) - estabeleceu a obrigatoriedade da educação ambiental em todos os níveis de ensino, consolidada na Constituição Federal de 1988, em um capítulo específico destinado à temática. Em 1997, foram lançados os Parâmetros Curriculares Nacionais (PCN), sendo que um dos volumes foi destinado ao meio ambiente, intitulado Meio ambiente e saúde. De acordo com o documento, a principal função da escola ao trabalhar com o tema é

contribuir para a formação de cidadãos conscientes, aptos para decidirem e atuarem na realidade socioambiental de um modo comprometido com a vida, com o bem-estar de cada um e da sociedade local e global. Para isso é necessário que, mais do que informações e conceitos, a escola se proponha a trabalhar com atitudes, com formação de valores, com o ensino e a aprendizagem de habilidades e procedimentos. E esse é um grande desafio para a educação. (Brasil. MEC, 1997, p. 25).

Vale ainda ressaltar que os PCN de ciências naturais do terceiro e do quarto ciclos do ensino fundamental também trazem indicações referentes à "questão ambiental, envolvendo aspectos econômicos, políticos, sociais e históricos, [o que] acarreta discussões sobre responsabilidades humanas voltadas ao bem-estar comum e ao desenvolvimento" (Brasil. MEC, 1998, p. 41-42). Nesse sentido, em meio à crise ambiental pela qual o mundo passa, faz-se necessário um ensino de ciências que proporcione aos alunos condições de discutirem assuntos referentes ao tema, por meio de interlocuções que envolvam a participação da sociedade em suas várias dimensões, como a ética, a justiça social, a economia, a participação democrática, entre outras, dando condições aos alunos de entenderem os direitos e deveres pelos quais podem lutar (Vasconcelos; Freitas, 2012). 
Em meio aos complexos problemas ambientais, a proposição de soluções e a importância de integrá-los ao ensino, com vistas ao desenvolvimento de atividades/ações que possam explorar seus limites, se apresentam urgentes. Dessa forma, devem-se propor ações que contribuam para que as concepções ingênuas de meio ambiente sejam trabalhadas e entendidas como um processo de transformação.

Este estudo se ancora no referencial teórico e metodológico da Teoria das Representações Sociais (TRS), que se desenvolveu com base nos estudos do psicólogo Serge Moscovici, no processo de elaboração de seu trabalho final de doutorado, publicado em 1961. De acordo com a TRS, a concepção científica sobre a psicanálise e o que os grupos sociais compreendem sobre um objeto são situações de conhecimentos diferentes, sendo que entre esses saberes existe um espaço, o qual se denominou de representações sociais (RS). (Oliveira, 2004). Segundo Moscovici,

[...] a representação social é um corpus organizado de conhecimentos e uma das atividades psíquicas graças às quais os homens tornam a realidade física e social inteligível, se inserem num grupo ou numa relação cotidiana de trocas, liberam o poder da sua imaginação. (Moscovici, 1978, p. 28).

Tendo em vista que as RS são conhecimentos compartilhados por um grupo, destaca-se a existência de um objeto sobre o qual se sustenta uma rede de comunicação que pode ser modificada com o passar do tempo e das relações estabelecidas; logo, as RS não são as mesmas para todos os integrantes do grupo e podem sofrer mudanças dependendo do contexto sociocultural. Em conformidade, Jodelet (2001) afirma que os membros de um mesmo grupo, ao compartilharem conhecimentos sobre determinado objeto, têm possibilidade de construir uma RS que, por sua vez, pode ser contraditória a outras visões consensuais que compartilham outras RS. Assim ocorrem as trocas entre os grupos e a dinamicidade constante das representações. Moscovici (2003) destaca que as RS apresentadas sobre determinado objeto são produtos da sociedade em que vivemos, e não de um modo de pensar único, mas de uma construção social. As RS englobam os comportamentos e as práticas de interações entre objeto e grupo (Wagner, 2000).

Vale ressaltar que são consideradas duas classes para os sistemas de pensamento, sendo elas denominadas por Moscovici de universo consensual e universo reificado. O universo consensual (senso comum) está ligado às produções intelectuais humanas, que são produzidas por meio das interações sociais cotidianas, sendo esse universo responsável pela construção das RS. Já o universo reificado é aquele produzido e adotado com rigor científico, com objetividade e por meio de métodos reconhecidos pela ciência (Sá, 1993).

Nesse sentido, a TRS tem como pressuposto as teorias do senso comum que buscam compreender como o conhecimento se posiciona por meio da comunicação informal, sendo um conjunto de conceitos proferidos, que têm origem nas práticas sociais e diversidades grupais, constituindo-se 
em uma linguagem própria e uma natureza cujos princípios são norteados pelos valores e conceitos coletivos sobre o real. (Santos, 2005; AlvesMazzotti, 1994).

Nessa perspectiva, diante da crescente preocupação com os problemas ambientais e sendo historicamente a escola um espaço propício para a inserção e a discussão de tais assuntos (Azevedo; Fernandes, 2010), esta pesquisa teve como principal objetivo investigar as possíveis RS dos alunos do primeiro e do terceiro anos do ensino médio, de uma escola localizada na cidade de Maringá fundada há mais de 60 anos, acerca do termo indutor "problemas ambientais" e compará-las, na busca de compreender como o processo de formação contribui para a transformação das RS. A escolha do termo indutor pode ser justificada pela presença dele em discussões nos diferentes contextos sociais e, principalmente, nas mídias.

Os resultados obtidos com esta pesquisa colaboram para compreender como os alunos percebem os problemas ambientais e, com base nesses resultados, promover atividades escolares que contribuam para que o senso comum, que faz parte da vida cotidiana, seja percebido como fonte de transformações para uma sociedade que busca melhores condições de vida.

\section{Percurso metodológico}

A pesquisa foi realizada com alunos do ensino médio em um dos colégios estaduais situado na região central de Maringá, PR, fundado em 1946. Atualmente a escola conta com uma equipe de 70 pessoas entre professores e funcionários e 673 alunos, sendo 192 matriculados no ensino médio, distribuídos em seis turmas. Trata-se de uma instituição que tem várias parcerias em projetos de extensão e pesquisa com a Universidade Estadual de Maringá (UEM), o que facilitou nossa aproximação e o desenvolvimento do estudo nesse campo institucional. Cabe assinalar que a investigação ocorreu com autorização da direção e que todos os estudantes participaram como voluntários e assinaram o termo de consentimento livre e esclarecido. No caso de aluno menor de idade, o documento foi assinado pelos responsáveis.

O processo de desenvolvimento da pesquisa ocorreu em março de 2016 e contou com a permissão e o acompanhamento da professora de biologia. Dessa forma, foram cedidas duas turmas, uma do primeiro ano, composta por 23 alunos, e outra do terceiro ano, com 16 alunos, ambas do período matutino, somando 39 alunos que representavam $20 \%$ do total matriculado no ensino médio. Os alunos tinham idade entre 14 e 19 anos, sendo 25 do gênero masculino e 14 do gênero feminino, característica própria às duas turmas. A escolha dessas séries se justifica pelo fato de que o tempo de escolaridade influencia no processo de formação e transformação das RS. Concordamos que, "enquanto agem no mundo, os indivíduos não somente mudam o mundo, mas realizam mudanças em si mesmos" (Marková, 2006, p. 239). 
Para a identificação das RS, foi adotada a técnica de evocação livre de palavras (Sá, 2000), com base no termo indutor "problemas ambientais na cidade de Maringá, PR", conforme anexo. Nessa perspectiva, foi solicitado aos alunos que escrevessem as cinco primeiras palavras que viessem à mente e, depois, que as hierarquizassem de um a cinco, sendo a de número um a de maior relevância e a de número cinco a menos relevante. Esse processo de hierarquização permite ao sujeito reavaliar suas ordens, o que possibilita uma reorganização dos termos evocados cognitivamente (Naiff; Naiff; Souza, 2009; Rocha, 2009). Por fim, dissertaram sobre cada uma das palavras, explicando seus significados (Tomanik; Tomanik, 2002).

A análise dos dados foi realizada com base na abordagem estruturalista desenvolvida por Jean-Claude Abric (1984), um dos colaboradores de Moscovici, e consistiu na identificação de duas estruturas: elementos nucleares e periféricos. Os elementos nucleares são responsáveis pelo significado da representação, sendo que sua "ausência desestruturaria ou daria uma significação radicalmente diferente a ela" (Abric, 2001, p. 163). "Desacordos entre realidade e representação modificam, de início, os esquemas periféricos; depois, eventualmente, o núcleo-central, isto é, a própria representação" (Flament, 2001, p. 184). Nesse sentido, os elementos periféricos que se dispõem ao redor do núcleo central são menos resistentes a mudanças e funcionam como barreira para os elementos que compõem o núcleo (Magalhães Júnior; Tomanik, 2012).

Partindo da combinação dos critérios de frequência e hierarquia, a estrutura da RS do grupo foi classificada em elementos centrais e periféricos (Sá, 1996, 2000; Naiff; Naiff; Souza, 2009). Para a identificação desses elementos, foi determinada a média das Ordens Médias de Evocação (OME) em conjunto com a frequência média das evocações (Cortes Junior; Corio; Fernandez, 2009; Rocha, 2009), por meio da fórmula: $O M E=\Sigma_{1}^{\mathrm{n} P . G} / f$ : somatória $(\Sigma)$ do número de vezes em que a palavra foi evocada (P), em uma dada posição de grau de importância, vezes seu grau de importância (G), dividido pela frequência (f) com que a palavra foi evocada no total), reestruturada por Magalhães Júnior e Tomanik (2012). Para melhor compreensão, classificação e visualização dos elementos centrais e periféricos, os grupos semânticos foram sistematizados em quadros, conhecidos como quadros de quatro casas ou diagramas de Vergès (Abric, 1994 apud Sá, 1996).

No diagrama de Vèrges, os elementos pertencentes ao núcleo central se localizam no primeiro quadrante, tendo maior frequência e maior OME. No segundo e no terceiro quadrantes, são apresentados os elementos intermediários e, no quarto e último quadrante, os elementos periféricos, que foram pouco evocados e que possuem alta OME (Sá, 1996, 2000; Naiff; Naiff; Souza, 2009; Cortes Junior; Corio; Fernandez, 2009; Rocha, 2009; Marques; Oliveira; Gomes, 2004).

Considerando que os grupos pertencentes ao núcleo central e protegidos pelos elementos periféricos são aqueles que efetivamente compõem as RS, neste trabalho serão tomados, para efeito de discussão, somente os elementos pertencentes ao primeiro quadrante de Vèrges. 


\section{Resultados e discussões}

Foram realizadas análises das evocações livres das duas turmas pesquisadas, sendo registrada a quantidade de palavras evocadas pelas turmas e descartadas as palavras que tiveram frequência igual a um (Ferreira et al., 2005), porque não possuem, segundo Teixeira, Balão e Settembre (2008), importância em relação à representatividade do grupo.

Para os participantes da pesquisa que se encontravam no primeiro ano, foi registrado um total de 115 palavras, das quais 109 formaram 11 grupos semânticos que representaram as evocações dos alunos. A OME média foi de 3,0, e a frequência média (f), igual a 9,9. Por meio desses valores, elaborou-se o Quadro 1, no qual são apresentados os quatro quadrantes com os respectivos grupos semânticos que possivelmente compõem as RS.

\section{Quadro 1 - Palavras evocadas pelos alunos do primeiro ano do ensino médio participantes da pesquisa sobre "problemas ambientais na cidade de Maringá, $\mathrm{PR}^{\prime}(n=23)$}

\begin{tabular}{|c|c|c|c|c|c|}
\hline \multicolumn{3}{|c|}{$\begin{array}{c}\text { Elementos centrais } \\
1^{\circ} \text { quadrante }\end{array}$} & \multicolumn{3}{|c|}{$\begin{array}{l}\text { Elementos intermediários } \\
2^{\circ} \text { quadrante }\end{array}$} \\
\hline \multicolumn{3}{|c|}{$\begin{array}{l}\text { Alta f e baixa Ordem Média de Evocações } \\
\qquad \mathrm{f} \geq 9,9 \text { e OME }<3,0\end{array}$} & \multicolumn{3}{|c|}{$\begin{array}{l}\text { Alta f e alta Ordem Média de Evocações } \\
\qquad \mathrm{f} \geq 9,9 \text { e OME } \geq 3,0\end{array}$} \\
\hline Grupo semântico de palavras & Freq. & OME & Grupo semântico de palavras & Freq. & $\mathrm{OME}$ \\
\hline Poluição & 11 & 2,1 & Agentes poluidores & 17 & 3,1 \\
\hline \multirow[t]{3}{*}{ Poluição atmosférica } & 11 & 2,6 & Lixo/problemas sociais & 16 & 3,3 \\
\hline & & & Desmatamento & 17 & 3,1 \\
\hline & & & Poluição da água & 10 & 3,2 \\
\hline \multicolumn{3}{|c|}{$\begin{array}{l}\text { Elementos intermediários } \\
3^{\circ} \text { quadrante }\end{array}$} & \multicolumn{3}{|c|}{$\begin{array}{c}\text { Elementos periféricos } \\
4^{\circ} \text { quadrante }\end{array}$} \\
\hline \multicolumn{3}{|c|}{$\begin{array}{l}\text { Baixa f e baixa Ordem Média de Evocações } \\
\qquad \mathrm{f}<9,9 \text { e OME }<3,0\end{array}$} & \multicolumn{3}{|c|}{$\begin{array}{l}\text { Baixa f e alta Ordem Média de Evocações } \\
\qquad \mathrm{f}<9,9 \text { e OME } \geq 3,0\end{array}$} \\
\hline Grupo semântico de palavras & Freq. & $\mathrm{OME}$ & Grupo semântico de palavras & Freq. & OME \\
\hline Aquecimento global & 4 & 2,7 & Descarte do lixo & 8 & 3,3 \\
\hline Dengue & 9 & 1,4 & Bueiros entupidos & 3 & 3,7 \\
\hline & & & Terrenos abandonados & 3 & 4,0 \\
\hline
\end{tabular}

Fonte: Adaptado pelos autores com base em Abric (1984).

No Quadro 1, percebe-se que o núcleo central das RS é representado por dois grupos semânticos, o da "Poluição" e o da "Poluição atmosférica". Apesar de os dois grupos fazerem referência ao termo "poluição", eles foram separados pelo processo da leitura e da análise das explicações redigidas pelos alunos para cada palavra citada. O grupo semântico denominado "Poluição", de $\mathrm{f}=11$ e OME $=2,1$, é composto apenas pelo 
termo "poluição"; dessa forma, as explicações dos alunos não fazem referência à poluição atmosférica, mas abordam o termo de forma geral, conforme os exemplos a seguir:

Aluno 4: A poluição é muito séria, poluir o meio ambiente.

Aluno 19: Uma das coisas que também temos que cuidar, como evitar jogar objetos no rio, ruas, isso traz muitos problemas.

Aluno 22: Fábricas que descartam suas coisas em lugares como rios e outros lugares.

Diante dessas explicações, entende-se que os alunos compartilham de uma ideia de poluição e reconhecem os efeitos acerca da capacidade de destruição, conforme afirma A4, ao indicar que é muito sério o ato de poluir o meio ambiente, que precisa ser cuidado. O aluno A19 explicita a necessidade de se evitar o descarte de objetos em lugares inapropriados, como rios e ruas, e A22 menciona as fábricas como agentes da poluição ambiental.

É possível compreender, pela análise do Quadro 1, bem como pelo discurso dos alunos, que a poluição está relacionada à imagem de objetos que são descartados e atirados contra a natureza, os quais são conhecidos como lixo pela sociedade em geral. Essa representação se coaduna com os resultados encontrados por Castro, Elias Filho e Silva (2013) em uma pesquisa sobre a RS do lixo. Na ocasião do estudo, a RS da poluição se mostrou centrada na imagem do lixo e da sujeira.

Em relação ao segundo elemento nuclear, "Poluição atmosférica", que apresentou $\mathrm{f}=11$ e $\mathrm{OME}=2,6$, percebe-se por meio das descrições do termo que os alunos ressaltam os problemas encontrados e os agentes motivadores:

A2: Na maioria das vezes causada por automóveis e indústrias que poluem liberando o gás carbônico na atmosfera afetando a camada de ozônio, causando o aquecimento global.

A9: Acontecem com fumaças tóxicas, retiradas de fábricas, carros e queimadas.

A23: Acontecem por causa de fumaça de veículos nas ruas, quando queimam lixo, árvores, várias coisas. Eu acho importante que isso não aconteça porque é o ar que nós respiramos.

Os alunos A2, A9 e A23, que representam o grupo semântico "Poluição atmosférica", fazem referência à emissão de fumaça no ar, sendo carros e fábricas citados como principais causadores desse problema. A23 faz referência à queima do lixo e das árvores como precursora da poluição atmosférica, prejudicando o ar que respiramos. Nesse grupo, as descrições estão voltadas aos problemas causados pela poluição à atmosfera, à qualidade do ar. Dessa forma, os termos foram desmembrados em "Poluição", ao abordar a poluição de forma geral, e "Poluição atmosférica", 
ao se observar vários alunos que citaram apenas o referido termo, explicitando assim sua diferenciação com o grupo semântico denominado apenas como "Poluição".

Para os alunos participantes da pesquisa que se encontravam no terceiro ano do ensino médio, foram obtidas 79 palavras evocadas, sendo descartadas quatro, por terem $\mathrm{f}=1$. O arranjo semântico resultou em 15 grupos, os quais foram organizados no Quadro 2 por meio dos valores da $\mathrm{f}$ média $=5,8$ e da OME média $=3,0$.

\section{Quadro 2 - Palavras evocadas pelos alunos do terceiro ano do ensino médio participantes da pesquisa sobre \\ "problemas ambientais na cidade de Maringá, $P R "(n=16)$}

\begin{tabular}{|c|c|c|c|c|c|}
\hline \multicolumn{3}{|c|}{$\begin{array}{l}\text { Elementos centrais } \\
1^{\circ} \text { quadrante }\end{array}$} & \multicolumn{3}{|c|}{$\begin{array}{l}\text { Elementos intermediários } \\
2^{\circ} \text { quadrante }\end{array}$} \\
\hline \multicolumn{3}{|c|}{$\begin{array}{l}\text { Alta f e baixa Ordem Média de Evocações } \\
\qquad \mathrm{f} \geq 5,8 \text { e OME }<3,0\end{array}$} & \multicolumn{3}{|c|}{$\begin{array}{l}\text { Alta f e alta Ordem Média de Evocações } \\
\qquad \mathrm{f} \geq 5,8 \text { e OME } \geq 3,0\end{array}$} \\
\hline Grupo semântico de palavras & Freq. & OME & Grupo semântico de palavras & Freq. & OME \\
\hline Poluição & 13 & 2,5 & Reciclagem & 11 & 4,0 \\
\hline Descarte do lixo & 11 & 2,0 & Poluição atmosférica & 10 & 3,2 \\
\hline Lixo/problemas sociais & 6 & 2,3 & Agentes poluidores & 9,0 & 3,4 \\
\hline \multicolumn{3}{|c|}{$\begin{array}{l}\text { Elementos intermediários } \\
3^{\circ} \text { quadrante }\end{array}$} & \multicolumn{3}{|c|}{$\begin{array}{l}\text { Elementos periféricos } \\
4^{\circ} \text { quadrante }\end{array}$} \\
\hline \multicolumn{3}{|c|}{$\begin{array}{l}\text { Baixa f e baixa Ordem Média de Evocações } \\
\qquad \mathrm{f}<5,8 \text { e OME }<3,0\end{array}$} & \multicolumn{3}{|c|}{$\begin{array}{l}\text { Baixa f e alta Ordem Média de Evocações } \\
\qquad \mathrm{f}<5,8 \text { e OME } \geq 3,0\end{array}$} \\
\hline Grupo semântico de palavras & Freq. & OME & Grupo semântico de palavras & Freq. & OME \\
\hline Desmatamento & 5 & 3,0 & Cuidados com as árvores & 5 & 4,0 \\
\hline Dengue & 4 & 2,5 & Fossa & 3 & 3,3 \\
\hline Trânsito/acidentes & 2 & 3,0 & Desperdício & 2 & 3,5 \\
\hline Terrenos abandonados & 2 & 3,0 & & & \\
\hline Bueiros entupidos & 2 & 2,5 & & & \\
\hline
\end{tabular}

Fonte: Adaptado pelos autores com base em Abric (1984).

Ao analisar o Quadro 2, percebe-se que os grupos semânticos que fazem parte do núcleo central são provavelmente "Poluição", "Descarte do lixo" e "Lixo/problemas sociais".

Dos três grupos pertencentes ao núcleo central das RS dos alunos, apenas o grupo "Poluição" coincide com um dos grupos do núcleo central dos alunos do primeiro ano participantes desta pesquisa. Os outros dois fazem referência ao lixo; consequentemente, considera-se que é bastante forte a presença desse termo entre as possíveis RS dos alunos.

O grupo semântico denominado "Poluição", por apresentar novamente duas especificações bem distintas entre as explicações dadas aos termos pelos alunos, foi novamente dividido em "Poluição" e "Poluição atmosférica"; no entanto, este último grupo pertence agora aos elementos intermediários das RS, os quais não serão tomados como objeto de discussão. Vale ressaltar que o grupo "Poluição", formado pelas evocações dos alunos do terceiro 
ano, apresentou $\mathrm{f}=13$ e OME $=2,5$, enfatizando fatores como grande quantidade de carros nas ruas emitindo gás carbônico, descarte de lixo em rios, terrenos vazios e mal cuidados, enfim situações que prejudicam o meio ambiente e que, em sua maioria, de acordo com os alunos, são causadas pela ação do homem, conforme destacado nas explicações para o termo "poluição" a seguir:

A4: Latas vazias mal cuidadas com mato grande e as pessoas jogam lixo, bueiros entupidos.

A12: A poluição ocorre quando agride a natureza de alguma forma.

No entanto, da mesma forma que ocorreu com o termo "Poluição", também com o termo "Lixo" foi necessário separar os alunos em dois grupos, já que, por meio da análise das explicações, foram percebidas diferenças nas atribuições de significados. Por esse motivo foram dissociados, recebendo as denominações: "Descarte do lixo", com f = 11 e $\mathrm{OME}=2$, e "Lixo/saúde", $\operatorname{com} \mathrm{f}=6$ e OME $=2,3$.

Assim, referente ao grupo denominado "Descarte do lixo", ao dissertarem sobre os termos que compuseram o grupo semântico, os alunos apresentaram uma visão distorcida dos materiais não utilizados mais pela sociedade. Algumas dessas explicações são:

A2: O lixo é o acúmulo de várias coisas que as pessoas não usam e jogam fora, às vezes jogam na rua e causa outros problemas.

A14: Vivemos em uma cidade muito verde, e bonita, com toda certeza, mas as pessoas não conseguem respeitar isso, vejo lixo em quase todos os lugares, bosques, universidade (UEM), ruas e principalmente terrenos isolados, e assim prejudicam nossa cidade.

A16: Terrenos baldios, onde as pessoas muitas vezes depositam lixo degradando a natureza.

O aluno A2, além de uma breve explicação do que é o lixo, faz referência ao descarte de objetos na rua e aos problemas causados por essa ação. Já A14 reconhece que uma das características marcantes da cidade onde a pesquisa foi realizada é ter bastante verde, mas aborda também os problemas do descarte de lixo, que pode ser encontrado em vários locais; e A16 apresenta a condição do lixo em terrenos baldios, o que, segundo ele, causa problemas à natureza. Nesse sentido, é identificável, novamente, que a RS do lixo, tangível nos discursos dos alunos, está centrada em objetos descartáveis, firmando e associando a presente pesquisa aos resultados de Castro, Elias Filho e Silva (2013).

O grupo "Lixo/saúde" foi assim denominado por apresentar, junto ao termo em questão, aspectos relacionados à saúde que são provocados pelo destino inadequado do lixo.

A1: Sujeiras nas ruas que a população joga e ninguém limpa, acumula água e dá dengue.

A8: São resíduos jogados em terrenos que podem acumular água e também estraga a paisagem. 
A10: Tipo tem gente porca que não cuida e joga lixo nesses terrenos, além de feder, traz doenças.

Entre as explicações dos alunos, além do lixo, verificam-se outros problemas socioambientais desencadeados pelo descarte inadequado; por exemplo, a proliferação de doenças como a dengue, causada pelo acúmulo de água em objetos jogados nas ruas, o que foi citado por A1. Ainda A8, ao dissertar sobre o termo "lixo", destaca dois problemas: o acúmulo de água e a poluição visual, sendo que as duas situações são causadas pela má gerência do lixo realizada pela população, o que contribui para o aumento de doenças, além de "estragar a paisagem", conforme descrito pelo aluno ao dizer que o acúmulo de lixo também provoca situações desagradáveis aos olhos da população. As mesmas constatações referentes ao termo "lixo" também foram encontradas na explicação de A10, ao ressaltar novamente problemas como o mau cheiro e as doenças que afetam a saúde da população.

Ainda nessa perspectiva, cabe uma reflexão, com base no discurso dos alunos, acerca da atitude dos sujeitos sociais que contribui para a proliferação da degradação ambiental por meio do depósito de lixo em locais inapropriados, conforme mencionado pelos alunos 1, 8 e 10. Sobre isso, Polli e Camargo (2015) afirmam que, embora os efeitos negativos sejam conhecidos, ainda não há atitude que contribua para a preservação do meio ambiente. Cabe ressaltar que estudos como os de Castro, Elias Filho e Silva (2013), Ferreira et al., (2007) e Spinelli (2002) têm reforçado a necessidade de uma educação mais comprometida com o meio ambiente, que aborde aspectos socioambientais, éticos e políticos.

Comparando os grupos que representam o núcleo central das RS dos alunos que se encontravam no primeiro e no terceiro anos do ensino médio, percebe-se que são grupos distintos, já que, entre os alunos do primeiro ano, é forte a presença do termo referente a poluição e, entre os alunos do terceiro ano, o termo referente a lixo é o mais evidenciado; logo, considera-se que os alunos das diferentes turmas possuem diferentes núcleos, esperando-se, então, diferentes RS.

No entanto, em meio às respostas, é possível perceber que os grupos que formam o núcleo central constituído pelas evocações das duas turmas apresentam aproximações com o universo reificado, no entanto é quase imperceptível em suas falas a presença de aspectos sociais, culturais, econômicos, entre outros, caracterizando o possível compartilhamento de RS entre as duas turmas investigadas. Dessa forma, a TRS pode contribuir ao sinalizar os problemas a serem enfrentados no processo de ensino e aprendizagem, por meio dos grupos semânticos do núcleo central, e assim amenizar, no decorrer do processo de escolarização, as representações compartilhadas, de forma que passem a ser aceitas no universo reificado.

Ao evocarem as palavras que compuseram os grupos semânticos "Poluição" e "Poluição atmosférica" (alunos do $1^{\circ}$ ano) e "Poluição", "Descarte do lixo" e "Lixo/saúde" (alunos do $3^{\circ}$ ano), percebe-se uma visão de meio ambiente intocável, que não considera a condição de homem e natureza em um mesmo espaço. Nessa perspectiva, é possível afirmar que 
os alunos entendem os problemas ambientais com uma visão simplista, ligada a aspectos naturais do ambiente, destacando elementos que fazem referência a uma visão naturalista, como preservação e conservação da fauna e da flora (Carvalho, 2012). Por conseguinte, as reflexões sobre as questões socioambientais, segundo as quais todos os problemas de ordem natural ou social fazem parte do ambiente, encontram-se ausentes nas RS dos alunos investigados.

Nessa perspectiva de inserir na educação momentos de reflexão acerca dos problemas de natureza ambiental e social, Reigota (2010, p. 62) ressalta que a "educação ambiental como educação política está empenhada na formação do cidadão nacional, continental e planetário, baseando-se no diálogo de culturas e de conhecimento entre povos, gerações e gêneros".

Com base nessa concepção, é importante pensar no desenvolvimento, junto aos alunos, de atividades que promovam oportunidades de construção de conhecimentos relevantes e significativos e que desenvolvam a capacidade de argumentação com criticidade e tomada de decisões frente às situações da vida cotidiana. Logo, suas concepções acerca dos problemas ambientais podem ser modificadas, levando em conta novas visões que englobem a consciência socioambiental.

Em meio aos grupos semânticos formados pelos alunos que se encontravam no primeiro e no terceiro anos do ensino médio, não foram localizados aspectos que se relacionem a um ambiente que integre valores, sejam eles culturais, políticos ou econômicos. Também não foram encontradas relações entre os problemas ambientais e as condições sociais da cidade onde se localiza o colégio em que foi aplicada esta pesquisa.

\section{Considerações finais}

A interpretação dos dados a respeito das RS de alunos do ensino médio sobre os problemas ambientais da cidade onde vivem se constituiu, essencialmente, um processo que permite conferir significados aos diferentes núcleos obtidos no processo de análise para cada uma das turmas investigadas.

Para a turma que se encontrava no primeiro ano, os grupos semânticos, construídos com base nas respostas dos alunos que compuseram o núcleo central, estão fortemente ligados aos fatores relacionados com a poluição, sendo que esta precisou ser dividida em dois grupos, "Poluição" e "Poluição atmosférica", devido à expressividade acentuada dos alunos quando se reportavam à poluição atmosférica. Para os alunos que se encontravam no terceiro ano, o tema lixo foi o mais presente entre os elementos do núcleo central, sendo que esse tema também precisou ser dividido em dois grupos, "Descarte do lixo" e "Lixo/saúde", levando em conta a disparidade das explicações para cada um dos termos que compuseram os grupos semânticos. Essa diferença entre os núcleos das RS pode ser explicada com base na diferença de tempo de estudos no ensino médio. 
Apesar de as duas turmas apresentarem aproximação com o universo reificado, ou seja, afastando-se das RS, é possível concluir que existem RS presentes em suas visões de meio ambiente. Isso pode ser explicado porque, ao mencionarem os problemas ambientais que se encontram presentes na cidade, não abordam as situações sociais e culturais; ao contrário, possuem uma visão naturalista de meio ambiente, desconsiderando as relações que existem entre o homem e o meio. Portanto, tal fato suscita uma reflexão acerca dos estudos sobre o tema no ensino médio, já que, apesar de terem mudado os grupos semânticos das possíveis RS, os conhecimentos relacionados ao assunto pouco têm contribuído para a superação do senso comum.

Nesse cenário de escassas considerações e ações acerca dos problemas sociais que fazem parte do dia a dia das pessoas, como moradia, políticas públicas, crise econômica, desrespeito à diversidade cultural, conclui-se que ainda há muito a se fazer no contexto educacional, tomando como ponto de partida as complexas relações entre o ser humano e a natureza. No entanto, as reflexões aqui realizadas constituem-se indicadores de proposições que atentam, mais efetivamente, para questões socioambientais.

\section{Referências bibliográficas}

ABRIC, J. C. A theoretical and experimental approach to the study of social representations in a situation of interaction. In: FARR, R.; MOSCOVICI, S. (Orgs.). Social representations. Cambridge: University Press, 1984.

ABRIC, J. C. O estudo experimental das representações sociais. In: JODELET, D. (Org.). As representações sociais. Rio de Janeiro: Ed. da UERJ, 2001.

ALVES-MAZZOTTI, A. J. Representações sociais: aspectos teóricos e aplicações à educação. Em Aberto, Brasília, v. 14, n. 61, p. 60-78, jan./ mar. 1994.

AZEVEDO, D. S.; FERNANDES, K. L. F. Educação ambiental na escola: um estudo sobre os saberes docentes. Educação em Foco, Juiz de Fora, v. 14, n. 2, p. 95-119, set./fev. 2010.

BAZZO, W. A. Ciência, tecnologia e sociedade e o contexto da educação tecnológica. Florianópolis: Ed. UFSC, 2010.

BRASIL. Lei no 6.938, de 31 de agosto de 1981. Dispõe sobre a Política Nacional do Meio Ambiente, seus fins e mecanismos de formulação e 
aplicação, e dá outras providências. Diário Oficial da União, Brasília, 2 set. 1981. Seção 1, p. 16509.

BRASIL. Ministério da Educação (MEC). Parâmetros Curriculares Nacionais: meio ambiente - saúde. Brasília: MEC/SEF, 1997.

BRASIL. Ministério da Educação (MEC). Parâmetros Curriculares Nacionais: ciências naturais. Brasília: MEC/SEF, 1998.

BRUGGER, P. Educação ou adestramento ambiental. Florianópolis: Letras Contemporâneas, 1994.

CARVALHO, I. C. M. Em direção ao mundo da vida: interdisciplinaridade e educação ambiental. Brasília: IPE, 1998.

CARVALHO, I. C. M. Educação ambiental: a formação do sujeito ecológico. 6. ed. São Paulo: Cortez, 2012.

CASTRO, S. M. V.; ELIAS FILHO, M. R.; SILVA, K. C. S. Representação social de poluição: um estudo na cidade de Belém - Pará. In: CONGRESSO NACIONAL DE EDUCAÇÃO, 9., 2013, Curitiba. Anais... Curitiba: CONEDU, 2013.

CORTES JUNIOR, L. P.; CORIO, L.; FERNANDEZ, C. As representações sociais de química ambiental dos alunos iniciantes na graduação em Química. Química Nova na Escola, São Paulo, v. 31, n. 1, p. 46-54, fev. 2009.

DIAS, G. F. Educação ambiental: princípios e práticas. 9. ed. São Paulo: Gaia, 2004.

FERREIRA, V. C. P. et al. A representação social do trabalho: uma contribuição para o estudo da motivação. Estação Científica, Juiz de Fora, v. 1, p. 1-13, ago. 2005.

FERREIRA, C. F. B. et al. Análise das representações sociais sobre o meio ambiente de técnicos e professores das secretarias de educação e meio ambiente do município de Bacia de Campos - RJ. In: ENCONTRO NACIONAL DE PESQUISA EM EDUCAÇÃ EM CIENCIAS, 6., 2007, Florianópolis. Anais... Florianópolis: ENPEC, 2007.

FLAMENT, C. Estrutura e dinâmica das representações sociais. In: JODELET, D. (Org.). As representações sociais. Rio de Janeiro: Ed. da UERJ, 2001.

JACOBI, P. R. Cidade e meio ambiente: percepções e práticas em São Paulo. São Paulo: Annablume, 2000. 
JODELET, D. Representações sociais. Rio de Janeiro: Ed. da UERJ, 2001.

LEFF, E. Complexidade, interdisciplinaridade e saber ambiental. In: PHILIPPI JUNIOR, A. et al. (Org.). Interdisciplinaridade em ciências ambientais. São Paulo: Signus, 2000. Disponível em: <http://www. revistas2.uepg.br/index.php/olhardeprofessor >. Acesso em: 25 jan. 2017.

LEFF, E. Saber ambiental: sustentabilidade, racionalidade, complexidade, poder. Petrópolis: Vozes, 2001.

MAGALHÃES JÚNIOR, C. A. O.; TOMANIK, E, A. Representações sociais e direcionamento para a educação ambiental na Reserva Biológica das Perobas, Paraná. Investigações em Ensino de Ciências, Porto Alegre, v. 17, n. 1, p. 227-248, 2012.

MARKOVÁ, I. Dialogicidade e representações sociais: as dinâmicas da mente. Petrópolis: Vozes, 2006.

MARQUES, S. C.; OLIVEIRA, D. C.; GOMES, A. M. T. AIDS e representações sociais: uma análise comparativa entre subgrupos de trabalhadores. Psicologia: Teoria e Prática, São Paulo, n. especial, p. 91104, 2004 .

MOSCOVICI, S. A representação social da psicanálise. Rio de Janeiro: Zahar, 1978.

MOSCOVICI, S. Representações sociais: investigações em psicologia social. Petrópolis: Vozes, 2003.

NAIFF, D. G. M.; NAIFF, L. A. M.; SOUZA, M. A. As representações sociais de estudantes universitários a respeito das cotas para negros e pardos nas universidades públicas brasileiras. Estudos e Pesquisas em Psicologia, Rio de Janeiro, v. 9, n. 1, p. 216-229, 2009.

OLIVEIRA, E. M. Educação ambiental: uma possível abordagem. 2. ed. Brasília: IBAMA, 2000.

OLIVEIRA, M. S. B. S. Representações sociais e sociedades: a contribuição de Serge Moscovici. Revista Brasileira de Ciências Sociais, São Paulo, v. 19, n. 55, p. 180-186, 2004.

POLLI, G. M.; CAMARGO, B. V. Representações sociais do meio ambiente e da água. Psicologia: Ciência e Profissão, Brasília, v. 35, n. 4, p. 13101326, 2015. 
REIGOTA, M. Meio ambiente e representação social. 8. ed. São Paulo:

Cortez, 2010.

REIGOTA, M. O que é educação ambiental. 2. ed. São Paulo: Brasiliense, 2012 .

ROCHA, A. G. Representações sociais sobre novas tecnologias da informação e da comunicação: novos alunos, outros olhares. 2009. $314 \mathrm{f}$. Dissertação (Mestrado em Educação) - Universidade Católica de Santos, Santos, 2009.

SÁ. C. P. Representações sociais: o conceito e o estado atual da teoria. In: SPINK, J. M. (Org.). O conhecimento no cotidiano. São Paulo:

Brasiliense, 1993. p. 19-45.

SÁ, C. P. Núcleo das representações sociais. Petrópolis: Vozes, 1996.

SÁ, C. P. A representação social da economia brasileira antes e depois do Plano Real. In: MOREIRA, A. S. P.; OLIVEIRA, D. C. (Orgs.). Estudos interdisciplinares de representação social. 2. ed. Goiânia: AB Ed., 2000. p. 49-69.

SANTOS, M. F. S. A teoria das representações sociais. In: SANTOS, M. F. S.; ALMEIDA, L. M. (Orgs.). Diálogos com a teoria das representações sociais. Recife: Ed. UFPE, 2005. p. 13-19.

SPINELLI, L. S. F. Representações sociais de educação ambiental de alunos do curso de Licenciatura Plena em Pedagogia da Universidade Federal de Mato Grosso. 2002. Dissertação (Mestrado em Educação) Universidade Federal de Mato Grosso, Cuiabá, 2002.

TEIXEIRA, M. C. T. V.; BALÃO, S. M. S.; SETTEMBRE, F. M. Saliência de conteúdos de representação social sobre o envelhecimento: análise comparativa entre duas técnicas associativas. Enfermagem UERJ, Rio de Janeiro, v. 16, n. 4, p. 518-524, 2008.

TOMANIK, E. A.; TOMANIK, M. C. O ambiente conhecido: estudo das representações sociais sobre a natureza compartilhadas pelos adolescentes de Porto Rico, Paraná. Maringá, 2002. Disponível em: $<$ http://www.peld.uem.br/Relat2002/pdf/comp_social_econ_Ambiente. pdf >. Acesso em: 28 abr. 2017. Relatório técnico.

VASCONCELOS, E. R.; FREITAS, N. M. S. O paradigma da sustentabilidade e a abordagem CTS: mediações para o ensino de ciências. Amazônia: Revista de Educação em Ciências e Matemáticas, Belém, v. 9, n. 17, p. 89-108, jul./dez. 2012. 
WAGNER, W. Sócio-gênese e características das representações sociais. In: MOREIRA, A. S.; OLIVEIRA, D. C. (Orgs.). Estudos interdisciplinares de representação social. 2. ed. Goiânia: AB Ed., 2000. p. 3-25.

YIN, R. K. Estudo de caso: planejamento e métodos. 2. ed. Porto Alegre: Bookman, 2001.

Recebido em 16 de junho de 2017.

Solicitação de correções em 16 de novembro de 2017.

Aprovado em 14 de fevereiro de 2018. 


\section{ANEXO - Instrumento de coleta de dados}

Série:

Gênero: ( ) Masculino （）Feminino

Idade:

Quando se refere a "problemas ambientais na cidade de Maringá, PR", quais são as cinco primeiras palavras que vêm a sua mente? Após a escolha das palavras, enumere-as de 1 a 5, de acordo com o grau de importância que você atribui a cada uma delas.

\section{Palavras:}

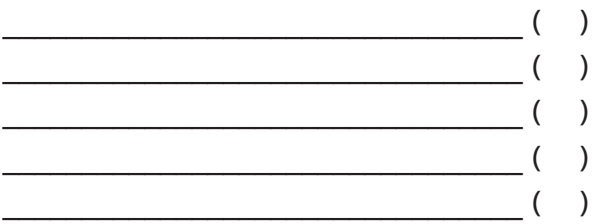

Escreva uma explicação para cada uma das palavras que colocou acima. 